\title{
Formas de dizer o indizível: a animação como recurso (testemunhal) em Postales de Leningrado e Infância
} Clandestina

\author{
Ways of saying the unspeakable: a resource as animation \\ (witness) in Postales de Leningrado and Infância Clandestina
}

\author{
Tânia SARMENTO-PANTOJA \\ Universidade Federal do Pará. \\ Bolsista Produtividade em Pesquisa (CNPQ)
}

\begin{abstract}
RESUMO: O estudo toma como corpus duas narrativas fílmicas: os filmes de ficção Postales de Leningrado e Infância Clandestina. São narrativas que tratam de aspectos relacionados à experiência com a ditadura em países da América Latina - respectivamente Venezuela e Argentina. Apresentam como protagonistas crianças, filhas e filhos de guerrilheiros na clandestinidade. Além da relação com as lutas estabelecidas por conta do regime de exceção, da experiência da clandestinidade e suas consequências avassaladoras para a vida, há um artifício técnico, o manuseio da animação, que desponta de modo peculiar nos dois filmes. Procedimento artístico que além de tornar mais próximas as duas narrativas estimula uma problematização importante para a teoria do testemunho: a agregação das técnicas de animação às narrativas de filmes com teor testemunhal favorecem a possibilidade de repensarmos aspectos próprios do testemunho, como a irrepresentabilidade do trauma? Pretendemos que esta questão conduza a análise dos objetos.
\end{abstract}

PALAVRAS-CHAVE: Infância. Exceção. Resistência. Cinema.

ABSTRACT: The study takes as corpus two filmic narratives: the moviefiction Postales de Leningrado and Infância Clandestina. They are narratives that deal with aspects related to the experience of the dictatorship in countries in Latin America - Venezuela and Argentina respectively. Both present as protagonists children, daughters and sons of fighters in hiding. In addition to the relationship with the struggles established due to the exceptional regime, theexperience of clandestinity and its overwhelming consequences for life, a technical device, the handling of the animation, which blunts in a peculiar way in both films. An artistic procedure that, in addition to making both two narratives close to each other, stimulates an important problematic for theory of testimony: does the aggregation of animation techniques to narratives movies with testimonial content favor the possibility to rethink aspects related to the testimony, as the unrepresentability of trauma? We intend this issue leads to the analysis of objects.

KEYWORDS: Childhood. Exception. Resistance. Cinema.

\section{Considerações iniciais}

A base epistemológica da narrativa de resistência é sempre a noção de enfrentamento envolvendo a alteridade. É sempre as condições do outro que é transformado em um problema a ser debatido no interior da narrativa de resistência. É uma narrativa que sempre parte da questão: quem é o outro? Ao que esse outro pode estar sujeito por ser justamente o outro da história, da situação, do discurso, do conflito armado, do estado de exceção? 
Considerando essas questões o estudo que ora apresento parte da dimensão narrativa e do território de onde se narra, para refletir como a criança, enquanto narradora, pode constituir-se em importante medium de organização narrativa quando a experiência da narração se mistura a um processo de memória comprometido com a reelaboração de determinados cenários históricos. O cenário histórico aqui evocado é o das experiências da ditadura no Cone Sul, mais particularmente na Venezuela e na Argentina, a partir de duas películas fílmicas: Postales de Leningrado e Infância Clandestina.

Além da caracterização histórica há pelo menos outros dois aspectos dignos de nota que aproximam as duas narrativas: o protagonismo infantil e a associação entre imagens realistas e imagens de animação. Quanto ao primeiro aspecto ressalto que a estratégia de composição narrativa pautada na mirada infantil em narrativas fílmicas em que estejam implicadas condições do estado de exceção é bastante conhecida na filmografia contemporânea. É o caso, por exemplo, de O labirinto do Fauno, A língua das mariposas, A culpa é do Fidel, Vozes inocentes, Machuca, O ano em que meus país saíram de férias.

No que concerne ao uso das associações entre realismo e animação, desde o Teatro Óptico a animação tem sido uma alternativa artística significativa quando o objetivo é a busca por efeitos que representem determinadas atmosferas, em particular as que projetam processos memorialísticos, fantasiosos, oníricos etc.

Por sua vez, a memória tem o poder de ativar e de reter, de selecionar e excluir e o faz com base em um conjunto de reminiscências articuladas. Reminiscência aqui é parte da produção sobre a infância, que por sua vez, na narrativa cinematográfica, se encontra constituída da reunião e da costura de elementos que formam um patchwork dessa vivência. Nesse processo o manejo da animação se configura como importante recurso formal capaz de dar corpo ao elemento "retido" na memória daquele que recorda, ou seja, a criança. Nesse sentido, nessas narrativas cinematográficas, as imagens em animação representam aquilo que é memória em condição metarreflexiva ou autoconsciente, na medida em que a memória é memória (re)apresentada, em um processo condizente com o que Jean-Luc Nancy (2015, p.62) chama a "méthexis da mimesis", marca do trabalho com a imagem, compreendida como 
O desejo de ir ao fundo das coisas, ou melhor, dito de outro modo, o desejo de deixar esse fundo subir à superfície. Desde que grava e pinta nas cavernas - no lugar de se contentar de olhar figuras e objetos, como queria Platão -, o homem não exerce outra, ou não é ele mesmo exercido por outra coisa senão por esse seu desejo e prazer de ir a fundo. Aí está toda a questão da arte (NANCY, 2015, p.62).

Vale ressaltar que as cenas encampadas pela animação, nos filmes sob análise, são cenas em que certamente está presente a dificuldade de comunicar impressões e sentimentos. Contudo, apesar dessa dificuldade de comunicar há um "desejo de real", não desjungido do regime de visualidade predominante no Século XXI e fundamentalmente baseado na "tentativa de tornar visível o que não é percebido pelo olho humano e por outro lado representar com fidelidade o que se entende por "real"" (MARTINS, 2013, p.48), ainda que essa demanda por fidelidade revele justamente o contrário do que é buscado: essa fidelidade ao real é relativa e por vezes ilusória.

Nesse sentido, se a técnica da animação consiste em dar vida ao inanimado (desenho) a partir de uma sequência rápida de imagens estáticas, que dessa forma ganham movimento, a proximidade com o real conferido à animação pode ser compreendida com base em uma tripla ordem no campo ôntico: primeiro, as cenas constituídas com base na animação assumem-se como realidade não física; segundo, correspondem a uma possibilidade de real, ou seja, o fato de algo existir apenas na forma de gravura, de desenho, não significa que não exista de fato; terceiro, há na técnica da animação certa autoconsciência acerca do lugar de si mesma no âmbito da construção das realidades, que não existe - ou é atenuada - em outras técnicas de captura do real.

Essa autoconsciência problematizadora, no âmbito da cinematografia, valoriza bastante o desenvolvimento da ideia de precarização da memória ou de como o que vemos pode ser pervertido e convertido em um conhecimento que nem sempre ou quase sempre não corresponde aos fatos. Ou se correspondem mostram que aquilo que construímos como um conhecimento resulta de algo enfim produzido, criado.

A título de exemplo: $O$ homem duplo, produção cinematográfica norteamericana, de 2006, dirigido por Richard Linkleiter, conta a história de um policial (vivido pelo ator Kenu Reaves), que atua infiltrado em um cartel de drogas. O uso de drogas, e em particular de uma droga muito perigosa, é praticamente uma obrigação 
para o policial não ser desmascarado quando infiltrado entre os traficantes, mas o uso da droga faz com que aos poucos o protagonista não consiga mais discernir o que é realidade e o que é alucinação. Nesse caso, a técnica de animação conhecida como rotoscopia, em que as cenas são previamente gravadas com atores e depois são pintadas quadro a quadro com um software, é aplicada para dar um efeito de realidade alternativa composta a partir da perspectiva paranóide dos personagens.

Outro filme que também utiliza animação é o documentário Valsa com Bashir, mas aqui a animação serve à problematização acerca da memória do massacre de Sabra e Shatila, ocorrido no Líbano, em 1982, quando aproximadamente três mil pessoas foram mortas. O filme é composto como se fosse um romance gráfico (grafic novel), com base em reportagens gráficas, desenhadas por Joe Sacco. Valsa com Bashir tem como protagonista o próprio diretor, em busca de elucidar suas lembranças sobre o massacre. Nesse processo a memória é tratada como uma zona penumbrosa, povoada de recordações nem sempre confiáveis, além disso, a narrativa do filme assinala os mecanismos seletivos da memória: o que silenciamos e porque silenciamos.

Essa tripla ordem de que falei anteriormente estão presentes em Postales de Leningrado e Infância Clandestina e tem uma importância capital, pois as cenas de animação ora estão relacionadas ao modo como a compreensão das coisas é construída (Postales de Leningrado), ora dão corpo às experiências traumáticas envolvendo as vivências no interior do estado de exceção, que prevalecem sobre as descobertas sexuais e amorosas e por isso geram profundos estados de tensão e angústia (Infância Clandestina). Mediada pela fantasia (Postales de Leningrado) ou pelo estado onírico ou devaneio (Infância Clandestina) a animação corresponde àquelas realidades somente viáveis na memória e pela memória.

De modo que aquela autoconsciência a qual me reporto anteriormente parece ficar ainda mais evidente quando temos diante de nós uma narrativa fílmica que faz uso de recursos mistos quanto ao modo de tratar a realidade. A seguir apresento uma análise de como esses recursos se fazem presentes nas duas narrativas. 


\section{Postales de Leningrado}

Postales de Leningrado (2007), direção de Mariana Rondón, é um filme marcado pelo protagonismo infantil e apresenta forte conteúdo autobiográfico. O relato é ambientado em 1966, durante a ditadura na Venezuela. A narração é feita a partir da perspectiva de crianças, cujos genitores são guerrilheiros. Essas crianças contam a experiência vivida pelos pais com base no modo como a percebem.

A perspectiva infantil é assim elemento estruturante que permite à narrativa constituir-se como simulacro das percepções infantis e, nesse processo, à narração de primeira ordem são abarcadas narrativas de segunda ordem: fotografias, animações etc. A narrativa é narrada por uma menina, anônima, de aproximadamente oito anos, que conta através de cartas e cartões postais sua história ao primo, Teo, nascido em

Figura 01: Capa Postales de Leningrado
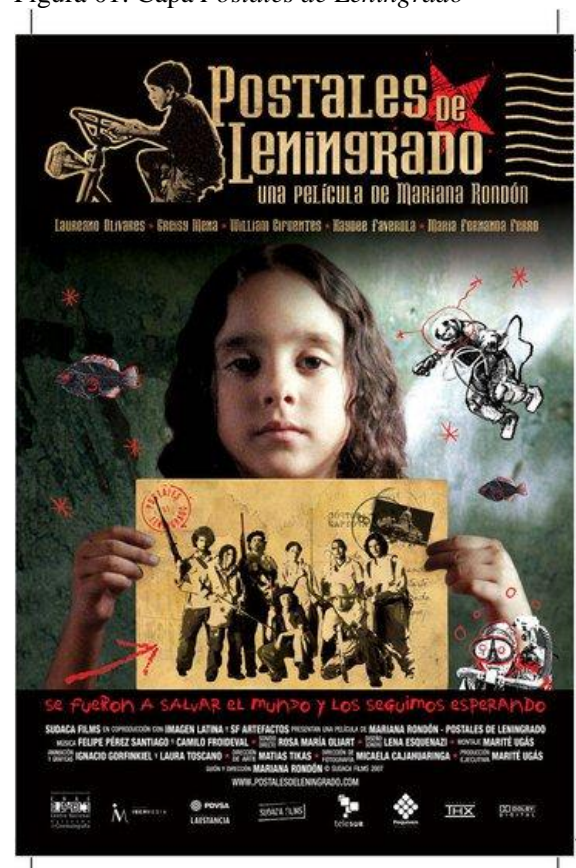

Fonte: http://pelismegahd.net/postales-deleningrado-online/ uma pequena cidade venezuelana e criado pela avó paterna. De forma que:

Son recurrentes dentro del filme las referencias a la figura femenina, que no sólo es omnipresente, sino que además ocupa un rol protagónico, especialmente desde el tema de la maternidad, que le da apertura y cierre al largometraje y que se mantiene presente de forma transversal en toda la obra (OLIVARES, 2012, p.74) ${ }^{1}$.

Teo e a prima narradora são filhos de guerrilheiros. Essa condição invade o cotidiano das crianças: seus passatempos e brincadeiras estão marcados por alusões às ações de valentia, aos esconderijos, aos anonimatos, dissimulações e fugas. Diversas situações relacionadas a experiência militante dos pais são recontadas segundo a compreensão dos filhos e por isso mesmo recebem o filtro da recriação de acordo com a

\footnotetext{
${ }^{1}$ Em tradução livre: "São recorrentes no filme as referências à figura feminina, que não somente é onipresente, mas ocupa um papel protagônico, especialmente na questão relacionada ao tema da maternidade, que abre e fecha o filme e permanece de forma transversal em toda a obra".
} 
lógica do universo infantil. A pequena guerrilheira e o menino nunca se encontraram e o mundo da guerrilha é compreendido por Teo, a partir da leitura das cartas e postais enviados pela prima.

A menina acompanha a mãe, Marcela, e sua história está ligada à guerrilha rural: sua mãe, guerrilheira, fica grávida de um dos companheiros de militância. Desde seu nascimento a menina a acompanha nas ações de guerra e serve também como forma de reforçar o anonimato da mãe. Elas vivem em constante estado de clandestinidade. Ainda de acordo com Rosa Chiquinquirá Raydán Olivares (2012, p.76):

Es importante nombrar a la narradora del filme. Una niña que a pesar de su corta edad - unos siete u ocho años - ya ha experimentado los horrores de la guerra y conoce bien los peligros que las persiguen a ella y a su madre, quienes viven en una eterna clandestinidad. Su narración, a pesar de estar hecha en un lenguaje que revela la cualidad infantil de la niña, deja traslucir toda la dureza del conflicto. Ella está consciente de que debe cambiarse de nombre con frecuencia, que la traición está presente en el entorno cercano y que su madre corre permanente peligro de muerte, y se pregunta cuál será su destino en caso de quedar huérfana ${ }^{2}$.

Apesar de muito pequena sua fala está eivada dos perigos que assombram sua existência e, sobretudo, de um sofrimento que não se encontra em pleno estado de consciência, pois o universo da guerra contra o estado autoritário e consequentemente a experiência da exceção é o único que ela conhece até aquele momento. Tudo o que ela conhece a respeito do mundo está restrito à experiência cotidiana dos acampamentos e esconderijos por onde se desloca com a mãe e os outros guerrilheiros. A vida ordinária, o cotidiano sem guerra é algo que ela desconhece completamente.

Todos os aspectos relacionados à sobrevivência nessas condições são, portanto, percebidos pela menina como parte da vida comum. Ela sabe que tem de trocar de nome a todo instante, de que precisa ter cuidado com os delatores, e o mais dramático: ela sabe que a mãe pode ser apanhada e assassinada a qualquer momento. Aliás, a narrativa é muito nucleizada em torno da ideia de dissimulações, disfarces e fugas para sobreviver.

\footnotetext{
${ }^{2}$ Em tradução livre: "é importante citar a narradora do filme. Uma menina que, apesar da sua tenra idade - alguns sete ou oito anos - já experimentou os horrores da guerra e sabe os perigos que assombram a ela e sua mãe, que vivem em eterna clandestinidade. Sua narrativa, apesar de ser feita em uma linguagem que revela a qualidade de criança menina, desmente toda a dureza do conflito. Ela está consciente de que devem se mudar frequentemente, sabe que a traição está presente no ambiente imediato e que sua mãe vive em permanente perigo de morte, e se pergunta qual será o seu destino se vier a se tornar órfâ".
} 
Vale destacar ainda que o filme apresenta uma linguagem metarreflexiva, de matriz fortemente iconoclasta, com uso proeminente do mise em abyme, a partir das inserções de fotografias e de animações estilizadas que se apresentam no interior de uma narrativa realista e portanto, as fotografias e as animações se encontram integradas a esta. Dessa forma a narrativa oscila o tempo todo entre a forma realista e a forma animada.

No que concerne aos artifícios técnicos, próprios do cinema o manuseio dessa estratégia está pontuada por tratamentos da imagem e intervenções digitais diversificadas, mas todas baseadas na técnica da animação, que aqui é fundamentada na ideia de colagem. Essa fixação na colagem é se tem dúvida vital para a narrativa, na medida em que projeta o universo criativo infantil, capaz de juntar os mais diversificados materiais e objetos para compor um jogo. Essa habilidade em reunir objetos díspares para compor outro objeto, com significação própria e nova espelha de maneira alegórica a vida estilhaçada, particularmente a infância estilhaçada. Além da ideia de colagem, há momentos no filme em que é utilizado o recurso da fotografia difusa, o que problematiza ainda mais a fronteira entre realismo e animação, entre real e criação, entre aquilo que é e aquilo que se imagina que seja.

\section{Infância Clandestina}

Infância Clandestina, filme de ficção, de 2012, dirigido por Benjamin Ávila, conta a história de um menino de 11 anos chamado Juan, cujo codinome é Ernesto. Ernesto é filho de um casal de "montoneros" que voltam à Argentina, na clandestinidade, depois de passarem um tempo escondidos no Brasil. Assim como em Postales de Leningrado o caráter autobiográfico é bastante presente: o filme é baseado na experiência vivida pelo próprio diretor, filho de montoneros. Seu pai foi assassinado durante um confronto com a polícia e sua mãe foi sequestrada e permanece desaparecida. 
Após o retorno a família, composta de pai, mãe, o menino, uma bebê de pouco mais de um ano, e mais um tio do menino, passam a viver em um vilarejo, numa casa atrás de uma fábrica de amendoim. O local que lhes serve de residência e meio de vida funciona como um refúgio a auxiliá-los nos disfarces necessários à composição da vida clandestina em meio urbano. De modo que oficialmente parecem ser uma família comum, que produz e comercializa tabletes de amendoim, mas na verdade utilizam essa condição para manter e favorecer as atividades como montoneros.

A narrativa se concentra no personagem Ernesto, procurando mostrar como o

Figura 02: Capa de Infância Clandestina

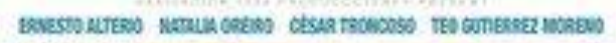

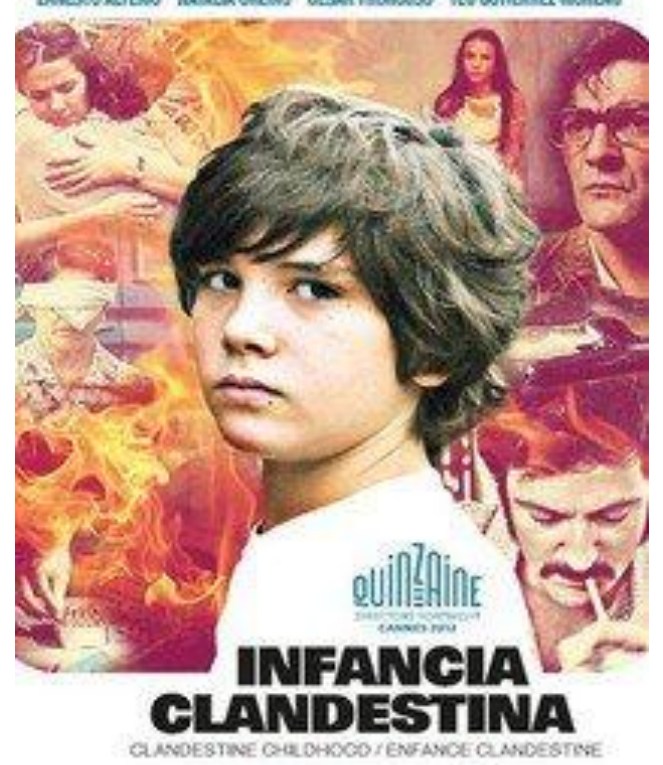

a film by Benjamin Árito

Fonte: https://filmow.com/infancia-clandestina-t57009/ cotidiano do menino é marcado pela precariedade, especialmente pela contínua experiência do provisório, assinalada pelo medo, pela perseguição, fugas e disfarces, que nem sempre são compreensíveis para o menino e de como, em meio a tudo isso, ele ainda tenta levar uma vida normal, na medida em que procura vivenciar o trânsito da infância para a adolescência: a descoberta do amor, da sexualidade, das transformações do corpo e nesse processo descobre que mesmo os atos de rebeldia contra os pais, esses ritos de passagem próprios dessa etapa da vida, colocam sob risco de morte aqueles a quem ama. Rosani Ketzer Umbach e Valéria de Castro Fabrício (2015, p. 85) tem uma interessante leitura sobre as condições a que o garoto está sujeito, baseada no princípio da dualidade:

Permanentemente sobressaltado, busca equilíbrio entre as realidades duais que o circundam: a oficialidade do mundo externo, da escola, dos amigos, colegas e a necessária farsa criada por aqueles que ama e admira. Diante disso, seu universo íntimo se potencializa. Representar essa gama conflituosa que abarca os âmbitos externo e interno do personagem é uma das propostas do filme que, com êxito, traduz em imagens esses embates. 
E em meio a todo esse processo a narrativa aponta dramaticamente para um conjunto de perdas inexoráveis para o menino: primeiro o tio querido, e finalmente o pai e a mãe, todos mortos pelo braço armado. Ao final de tudo, a quase perda da irmã caçula, que depois de estar desaparecida é finalmente recuperada pela avó materna das crianças em um último e desesperador instante do filme. A vida do menino parece ao expectador, totalmente desmobilizada, na medida em que tudo a sua volta perece: a família, a casa, a fábrica de amendoim, o aconchego ainda que provisório, os disfarces, tudo vai derruindo rapidamente.

O estado de caos, o desespero, a experiência aterradora, precipitada e sufocante é reiterada pelas cenas em que a animação dá conta do pesadelo, por vezes literal, vivenciado pelo garoto. Momentos em que o drama da morte, da perda angustiada, o tomam de assalto. Os quadrinhos não são apenas pertinazes nos momentos em que deflagram no relato a fronteira entre duas formas de realismo - uma colada à história e a outra, alternativa, porque instaurada no espaço do onírico ou do devaneio. Outra fronteira também se estabelece: as cenas realistas são espaços da experiência contada enquanto as cenas animadas são espaços da experiência recordada.

\section{Duas considerações parciais}

Finalizo com uma questão: até que ponto o testemunho fundado na associação entre catástrofe (a vida virada para baixo, a vida precarizada) e trauma (o sofrimento inominável) ganha representabilidade em uma narrativa que utiliza esse tipo de procedimento: a animação? À guisa de uma tentativa (provisória) de resposta faço duas considerações parciais.

Entendo que a problematização acerca de como o real é construído não está desjungido do problema da irrepresentabilidade do trauma. A questão é que o trauma se estende aqui: ele não está sintetizado em uma ferida traumática, ele está depositado sobre a experiência e a embebe de tal maneira que a exceção e o sofrimento nela implicados se naturalizam, se tornam algo ordinário na e para a vida.

Em Infância Clandestina e Postales de Leningrado a imagem luta contra essa ordinarização do sofrimento, por isso, a experiência da exceção recebe o reforço da imagem diferenciada na forma da animação e ao mesmo tempo, ao valer-se desse 
recurso, duplica o papel da imagem no processo da realização do testemunho e da evocação da barbárie que deve ser combatida.

Narrar o impossível, o inominado: sempre um desafio. O hibridismo entre formas de realismo e, consequentemente, de gêneros da cinematografia observado nas duas películas, nos diz muito sobre esse desafio. O hibridismo desempenha em ambas uma força dramática reiterativa e voltada à questão da empatia, da relação com o horror, da necessidade de revisitá-lo.

A animação funciona como filtragem que amplifica a vida precária, mas ao mesmo tempo a reveste de certa leveza, tão própria da infância, ao dizer a dor de uma forma mais contida - na medida em que, nos momentos em que a película se assume como animação, se distância da forma mais realista e mais dilatada em ambos os filmes, e nesse sentido observo aí uma proximidade com a ideia (tão presente em Lessing e em Schiller) de um limite para a apresentação da dor (SELIGMANN-SILVA, 2009, p. 7879), que é ao mesmo tempo apropriativa e de rasura, justamente pela relação dialética promovida pelas hibridações de ordem formal.

Para além dessa relação complexa com os realismos vale ainda destacar o tropo da sobrevivência como um aspecto imanente em ambas as narrativas fílmicas, não apenas pela presença marcante do protagonismo infantil como alegoria da sobrevivência, mas, sobretudo, pela possibilidade de fazer do resíduo memorialístico o (re)encontro com um passado espectral sempre disposto a nos assombrar mais uma vez.

\section{Referências}

MARTINS, India Mara. "Desejo de Real” e busca pelo "Realismo". Revista ECO-Pós, v. 15 , n. 3, p. 47-68, 2013.

NANCY, Jean-Luc. Imagem, mímesis \& méthesis. In: ALLOA, Emmanuel (org.). Pensar a imagem. Belo Horizonte: Autentica Editora, 2015.

OLIVARES, Rosa Chiquinquirá Raydán. La mirada femenina en el cine venezolano. Dissertação de Mestrado. Programa de Maestría en Estudios de la Cultura. Universidad Andina Simón Bolívar - Sede Ecuador. Quito, 2010.

SELIGMANN-SILVA, Márcio. Para uma crítica da compaixão. São Paulo: Lumme Editor, 2009. 
UMBACH, Rosani Ketzer \& FABRÍCIO, Valéria de Castro. "Infância clandestina": A antítese como estruturadora do discurso de testemunho. Guavira Letras, Três Lagoas/MS, n. 20, p. 83-92, jan./jun. 2015

\section{FILMOGRAFIA}

POSTALES DE LENINGRADO. Direção: Mariana Rondón. Produção: Marite Ugas, Alberto Arvelo. Roteiro: Mariana Rondón. Venezuela (2007 ). DVD (93min).

INFÂNCIA CLANDESTINA. Direção: Benjamin Ávila. Produção: Benjamin Ávila e Luís Puenzo. Roteiro: Marcelo Muller. Argentina (2012). DVD (110min). 